\title{
Reducing contamination by exposure plus safety behaviour
}

Article

Accepted Version

Rachman, J., Shafran, R., Radomsky, A. and Zysk, E. (2011) Reducing contamination by exposure plus safety behaviour. Journal of Behavior Therapy and Experimental Psychiatry, 42 (3). pp. 397-404. ISSN 0005-7916 doi:

https://doi.org/10.1016/j.jbtep.2011.02.010 Available at https://centaur.reading.ac.uk/21694/

It is advisable to refer to the publisher's version if you intend to cite from the work. See Guidance on citing.

To link to this article DOI: http://dx.doi.org/10.1016/j.jbtep.2011.02.010

Publisher: Elsevier

All outputs in CentAUR are protected by Intellectual Property Rights law, including copyright law. Copyright and IPR is retained by the creators or other copyright holders. Terms and conditions for use of this material are defined in the End User Agreement.

\section{www.reading.ac.uk/centaur}

\section{CentAUR}

Central Archive at the University of Reading 
Reading's research outputs online 
Reducing Contamination by Exposure Plus Safety Behaviour ..

S. Rachman ${ }^{1 *}$, Roz Shafran ${ }^{2}$, Adam S. Radomsky $^{3}$ and Eva Zysk ${ }^{1,2}$

${ }^{1}$ Department of Psychology, University of British Columbia, Vancouver, Canada and Psychology Dept., Institute of Psychiatry,

De Crespigny Park, London SE5 8AF.

${ }^{2}$ School of Psychology and Clinical Languages Sciences, University of Reading, UK.

${ }^{3}$ Department of Psychology, Concordia University, Montreal, Canada. 
*Corresponding Author, UBC Dept. of Psychology, 2136 -West Mall, Vancouver, BC, V6T 1 Z4. e-mail, rachman@interchange.ubc.ca 


\section{Abstract}

Background and Objectives: It has been proposed that the judicious use of safety behaviour can facilitate improvements in the acceptability of cognitive-behaviour therapy (CBT). It was decided to explore the possibility of facilitating CBT by introducing a form of safety behaviour. We sought to assess the degree to which Exposure Plus Safety Behaviour (E+SB) is an effective intervention for contamination fears.

Methods: A comparison was made between the effects of a control condition (Exposure and Response Prevention; ERP) and an experimental condition (Exposure Plus Safety Behaviour; $\mathrm{E}+\mathrm{SB}$ ) in which each exposure to a contaminant was followed by the use of a hygienic wipe in a sample of $(n=80)$ undergraduate students. In session one, each participant touched a confirmed contaminant 20 times. After each exposure participants were asked to report their feelings of contamination, fear, disgust, and danger. In the second session, two weeks later, the same procedure was carried out for a further 16 trials.

Results: The ERP and the E+SB conditions both produced large, significant and stable reductions in contamination. Significant reductions in fear, danger and disgust were also reported in both conditions.

Limitations: The treatment was provided to an analogue sample and over two sessions. Conclusions: The use of hygienic wipes, the safety behaviour used in this experiment, did not preclude significant reductions in contamination, disgust, fear and danger. If it is replicated and extended over a longer time-frame, this finding may enable practitioners to enhance the acceptability of cognitive-behavioural treatments and boost their effectiveness. 
Keywords: Contamination; Disgust; OCD; Exposure Plus Safety Behaviour (E+SB); Exposure and Response Prevention (ERP); Cognitive Behaviour Therapy (CBT). 


\section{$\underline{\text { Reducing Contamination by Exposure Plus Safety Behaviour }}$}

\section{Introduction.}

Therapeutic safety behaviour can facilitate the reduction of fear (Rachman, Radomsky and Shafran, 2008), and because of the unacceptably large numbers of refusers and drop-outs in ERP treatment of OCD (see below), we decided to focus on the development of a judicious form of safety behaviour for this disorder. The particular type of safety behaviour introduced for this work was the use of a hygienic wipe after touching a contaminant. We began this work in the clinic with severe cases of OCD who had either not responded to ERP or been unable to tolerate ERP. Our exploratory use of a combination of exposure plus safety behaviour $(\mathrm{E}+\mathrm{SB})$ was encouraging and produced clinically significant benefits for 8 out of 10 OCD patients over a significant and sustained period of time (see Discussion). In order to buttress these results by experimental analyses of the processes involved in the E+SB combination, and to improve our understanding of safety behaviour in general, we carried out a laboratory test of E+SB.

The primary purpose of the present experiment was to test the hypothesis that repeated trials of Exposure Plus Safety Behaviour $(\mathrm{E}+\mathrm{SB})$ can produce reductions in feelings of contamination. The significance of this hypothesis is that several prevailing cognitive behavioural theories and therapies aver that engaging in safety behaviour impedes the reduction of fear and prevents the disconfirmation of maladaptive beliefs. Hence it is considered essential to prevent safety behaviour in order to make therapeutic gains. This is the response prevention component of ERP.

In 1966 Victor Meyer published a ground-breaking paper on the treatment of obsessive compulsive disorders (OCD). Influenced by the results from numerous laboratory experiments which demonstrated that the experimentally-induced fears displayed by cats, dogs and rats can be 
reduced by repeatedly exposing them to the fear stimuli while they are restricted in a lab chamber (Wolpe, 1958), Victor Meyer (1966) took the bold step of applying this information in the treatment of two patients who were severely incapacitated by OCD. They were given intensive in-patient treatment that consisted of repeated exposures to contaminants, and were prevented from carrying out their strong urges to wash and/or neutralize. The patients were provided with 24-hour nursing supervision, and Meyer even went so far as to cut off the water supply to their quarters. After many years of distress and disability, and numerous failed treatments, the patients made significant progress during Meyer's treatment. Stimulated by Meyer's example, his rudimentary Exposure plus Response Prevention method (ERP) was gradually refined and extended to out-patient care (Rachman \& Hodgson, 1980; Rachman et al., 1979).

ERP is an essential component of the prevailing therapy for OCD (Cognitive Behaviour Therapy, CBT). The method of repeatedly exposing the patient to fear-evoking stimuli and preventing any safety behaviour, is dependably effective (Barlow, 2001; Craske, 1999; Whittal et al., 2005; Foa et al., 2005), and strongly recommended by the U.K. National Institute for Health and Clinical Excellence (NICE, 2005), in addition to the U.S. National Institutes of Mental Health (NIMH, 2009), and the Obsessive-Compulsive Disorder Foundation (OCF, 2009).

ERP is a demanding and even distressing form of treatment, with unacceptably high refusal and drop-out rates (Jenike, Baer \& Minichiello, 1998; Clark, 2004; Cottraux, Bouvard \& Milliery, 2005; Foa, Liebowitz, Kozak, Davies, Campeas, Franklin, 2005; Stanley \& Turner, 1995, Whittal et al., 2005). A more tolerable, gentler form of treatment would be welcome. It has recently been proposed that the judicious use of safety behaviour, especially early in treatment, can facilitate and enhance treatment (Rachman, Radomsky \& Shafran, 2008). 
Safety behaviour can facilitate the treatment of acrophobia, specific phobias, claustrophobia, and agoraphobia (see de Silva and Rachman, 1984; Milosevic \& Radomsky, 2008; Parrish, Radomsky \& Dugas, 2008; Rachman et alia, 1986; Rachman, Radomsky \& Shafran, 2008, for examples and analysis). It was decided to test out the value of introducing safety behaviour in reducing contamination, one of the most common manifestations of OCD.

In the present experiment participants were trained to use wetwipes in order to reduce/remove the feelings of contamination that were provoked by touching confirmed contaminants. This procedure is a form of safety behaviour.

\section{Hypotheses.}

The primary hypothesis is that Exposure plus Safety Behaviour (E+SB) can effectively reduce feelings of contamination. The secondary hypothesis is that $\mathrm{E}+\mathrm{SB}$ can reduce the associated disgust, fear and danger perceptions that often follow exposure to contaminants.

\section{METHODS.}

\subsection{Participants.}

The 80 participants were student volunteers invited from the human subject pool of the Psychology Department of the University of British Columbia research panel. As can be seen in Table 1 the participants reported moderately high feelings of contamination response to touching a particular item (including lab specimens, a biological culture, a bin containing assorted rubbish, etc.) prior to engaging in the experimental exercise. The ratings of contamination, disgust, fear and danger were all rated on a scale from $0-100$, with 0 indicating 'not at all' and 100 indicating 'extremely high'. There were no exclusionary criteria for initial 
recruitment into the study and participants were given course credits for their cooperation. Ethics approval was obtained from the Behavioural Science Ethics Committee of the University of British Columbia. Participants were randomly assigned to the Control Condition (ERP) or to the experimental condition $(\mathrm{E}+\mathrm{SB})$. The ERP group had a mean age of $20.63(\mathrm{SD}=3.30)$ years and the E+SB group a mean of $20.52(\mathrm{SD}=3.12)$ years. There were 32 females in the ERP group and 28 in the E+SB group.

The control group participants were repeatedly exposed to a contaminating stimulus and refrained from engaging in any safety behaviour (ERP). In the experimental group the participants were also exposed repeatedly to a contaminating stimulus, but used wetwipes to clean their hands after each exposure (safety behaviour); the response prevention component was omitted $(\mathrm{E}+\mathrm{SB})$. The effects of the wetwipe exercises on subsequent feelings of contamination, disgust, fear and danger were the data of interest. All of the results of E+SB are the trial by trial responses of the participants after touching the contamination stimulus, and before they used the wipe. The effects of the E+SB condition were compared to the effects of the standard ERP condition.

\subsection{Assessments.}

In the pre-test each participant was asked to touch six potential contaminants (in randomized order) in order to select the item that elicited the greatest amount of contamination. The item that evoked the strongest feelings of contamination was used as the stimulus in all of the exposure trials (20 exposure trials in session one, and 16 exposure trials in session two).

\subsection{Procedure.}


The experiment consisted of two sessions of ERP or of E+SB, during which each participant was repeatedly asked to touch a selected contaminant. There was an interval of 1 week between sessions. (Full details of the procedure will be sent on request.)

During the first session, each participant had 20 exposures to the contaminant (i.e. 20

trials). In order to test the stability of any changes observed during Session One, after an interval of approximately two weeks, the participants in both groups were exposed to their original contaminant for an additional 16 trials. At the start of each exposure trial, participants were asked to touch the contaminant and then rate the amount of contamination experienced, and also the amount of fear, danger, and of disgust, using traditional 0 to 100 scales contamination. The ratings which the participants made after touching the contaminant, but before using a wipe, are the data of interest.

In the $\mathrm{E}+\mathrm{SB}$ condition the participants were asked to use a hygienic wipe to clean their hands after touching the contaminant, until the contamination was reduced to $20 \%$ or lower. In the ERP condition participants refrained from any washing or cleaning after each contact with the contaminant.

\section{INSERT TABLE 1 ABOUT HERE}

\subsection{The Contaminants.}

A total of six items were introduced to each participant: Rubbing the bottom of their shoes, handling grubby banknotes, rummaging in a partly filled garbage basket, handling an old grimy telephone, handling a sealed biohazard bag containing a testube labelled PATH 194, 
handling a second sealed biohazard bag containing used lab materials (discarded oral thermometer,etc).

Pilot data on the six items used in the study revealed that in a large sample $(n=197)$ from the same population of undergraduate students, the mean contamination rating of the most contaminated item was $84.67 / 100(\mathrm{SD}=95.5)$ and that the median contamination rating was 80 . Among the 80 participants enrolled in this study, the mean score for both groups in response to touching the contaminant was lower, but still high at 64.35. The ratings on trial one for the secondary reactions for both groups were high for disgust -- 70.7, but low for fear 28.5, and danger 23.5. Evidently reactions of disgust are readily evoked in lab conditions.

\subsection{Session One Procedure.}

Upon providing their informed consent, participants were told they would be asked to touch a number of items, and then rate their feelings of 1) contamination, 2) fear, 3) danger and 4) disgust. This set of four ratings is referred to as CFDD (contamination, fear, danger, disgust) in the present description. The scale for each ranged from 0 (not at all, e.g. not at all contaminated) to 100 (extremely/most imaginable, e.g., extremely contaminated), and a rating of 50 was moderate. Participants were told that they could use the full range of ratings, anywhere from 0 to 100.

\subsection{Baseline.}

In order to establish a baseline the participants were asked to handle each of the contaminating items and report their ratings (CFDD). The items were presented in random order. For each participant, the item that evoked the highest level of contamination was chosen as the contamination stimulus for the experimental trials.

\subsection{Experimental Trials.}


Participants in the Control condition, ERP, were asked to touch the contaminating stimulus and then rate their CFDD reactions. During the exposure trials and after each touch, they were not permitted to wash or cleanse themselves in any way, and none did so. They completed 20 trials during Session One and 16 trials during Session Two.

Participants in the experimental condition, ESB also completed 20 trials in Session One and 16 trials in Session Two. They were given additional instructions to use a hygienic wipe to clean away any contamination after each trial of touching the contaminant:

Ten trials were completed in this manner in each of the two conditions, ERP and ESB. Participants were then given a three-minute break. After the break, another 10 exposure trials were carried out. In this part of the experiment a 30-second delay was introduced. The control group had a 30 second delay after touching the contaminating item, and were then asked to report their ratings of CFDD. In the ESB group, the delay came after touching the item, and before participants were offered a wipe. The delay was introduced in order to enhance the effects of the procedure. The ratings of CFDD were taken after the delay, prior to the use of the wipe.

\subsection{Session Two Procedure}

Exposure Trials: Participants remained in the group to which they were initially assigned.

Participants completed 16 exposure trials that were identical to those in the post-break period of Part 1, namely delaying for 30 seconds before providing their CFDD ratings. At the end of the experiment, the participants were debriefed and given an opportunity to ask any questions about the study.

\section{THE PREDICTIONS.}


4.1 The main prediction was that ERP and E+SB would both produce significant reductions in feelings of contamination after repeatedly touching the selected contaminant stimulus. It was also predicted that these changes would be stable over time.

4.2 The secondary predictions were that both ERP and E+SB would:

(a) reduce the feelings of disgust after touching the stimulus, (b) reduce the fear reactions to touching the stimulus, and (c)reduce the sense of danger after touching the stimulus.

\section{RESULTS}

The mean scores for contamination, disgust, fear and danger, for the two conditions are displayed in Table 1 and Figures 1-4.

\subsection{Mutivariate analyses}

In order to examine the overall effects of the two conditions on all of the variables of interest (CFDD ratings), a 2 (condition) by 2 (visit, to assess for between-visit changes) by 2 (pre-post, to assess for within-visit changes) repeated measures analysis of variance (MANOVA) was conducted on the set of fear, danger, contamination and disgust scores obtained from participants.

Multivariate tests indicated that there were significant overall effects of condition, $\mathrm{F}(4,75)=7.73, \mathrm{p}<0.001$, partial $\eta^{2}=0.29$, visit, $\mathrm{F}(4,75)=10.83, \mathrm{p}<0.001$, partial $\eta^{2}=0.37$, pre-post, $\mathrm{F}(4,75)=32.09, \mathrm{p}<0.001$, partial $\eta^{2}=0.63$, as well as interactions between condition and pre-post, $\mathrm{F}(4,75)=11.18, \mathrm{p}<0.001$, partial $\eta^{2}=0.37$, visit and pre-post, $\mathrm{F}(4,75)=12.40, \mathrm{p}$ $<0.001$, partial $\eta^{2}=0.40$. A trend towards a significant three-way interaction between condition, visit, and pre-post was also found, $F(4,75)=2.41, p=0.057$, partial $\eta^{2}=0.11$. These findings were followed with more detailed univariate analyses in order to better understand the specific effects on CFDD variables. 


\subsection{Univariate analyses}

To obtain a more refined understanding of these results, follow-up univariate tests revealed that, across the two conditions, fear, contamination, danger and disgust each declined significantly both within $\left(F(1,78)>21.78, p<0.001\right.$, partial $\left.\eta^{2}>0.22\right)$, and between $(F(1,78)>$ 11.37, $\mathrm{p}<0.001$, partial $\left.\eta^{2}>0.13\right)$ sessions.

Participants in the ESB condition reported significantly lower contamination, $\mathrm{F}(1,78)=$ 22.16, $\mathrm{p}<0.001$, partial $\eta^{2}=0.22$, and disgust, $\mathrm{F}(1,78)=10.91, \mathrm{p}=0.001$, partial $\eta^{2}=0.12$, across all time points compared to the ERP condition, and a significant pre-post by condition interaction, $F(1,78)=37.22, p<0.001$, partial $\eta^{2}=0.32$, revealed that contamination scores decreased more in the ESB condition than in the ERP condition; this interaction was not significant for any of the other variables (i.e., only contamination, and not fear, danger or disgust), $\mathrm{F}(1,78)<1$, n.s., partial $\eta^{2}<0.01$.

The main finding was that the ERP control condition and the E+SB (wipes) condition produced significant reductions in contamination. The reductions after ERP and ESB were very large and did not differ between the conditions. The secondary findings were that both ERP and $\mathrm{E}+\mathrm{SB}$ also produced significant reductions in fear, danger, and especially in disgust.

\section{INSERT FIGURES 1-4 ABOUT HERE}

\subsection{The return of contamination.}

In order to detect any indications of a return of contamination between sessions (and possibly the return of danger, fear and disgust), a 2 (condition) by 2 (time) MANOVA was 
conducted on contamination, fear, danger, and disgust scores across the two time points defined by ratings on the last trial of the first visit, and the first trial on the second visit.

Multivariate results showed that there were main overall effects of condition, $F(4,75)=$ 7.79, $\mathrm{p}<0.001$, partial $\eta^{2}=0.29$, and time, $\mathrm{F}(4,75)=6.44, \mathrm{p}<0.001$, partial $\eta^{2}=0.26$, indicating that variables (CFDD) of interest did increase significantly between sessions and that ERP ratings were significantly higher than those in the ESB condition; but these findings were tempered by a condition by time interaction, $\mathrm{F}(4,75)=7.40, \mathrm{p}<0.001$, partial $\eta^{2}=0.28$, indicating that changes in the variables of interest over time were differentially effected by condition. In order to obtain a more detailed understanding of these findings in terms of individual CFDD variables, univariate tests were subsequently conducted.

Follow-up univariate analyses revealed that the return of fear, $\mathrm{F}(1,78)=4.30, \mathrm{p}=0.041$, partial $\eta^{2}=0.05$, return of danger, $\mathrm{F}(1,78)=5.50, \mathrm{p}=0.022$, partial $\eta^{2}=0.07$, return of contamination, $\mathrm{F}(1,78)=30.61, \mathrm{p}<0.001$, partial $\eta^{2}=0.28$, and return of disgust, $\mathrm{F}(1,78)=$ 21.28, $\mathrm{p}<0.001$, partial $\eta^{2}=0.21$ were larger in the ESB condition than in the ERP control condition. Although CFDD variables showed a return between sessions, it is important to note that Session Two trial 1 scores were lower than Session One trial 20 scores. That is, although there was a return of contamination, etc., they did not return to pre-experiment levels, multivariate $\mathrm{F}(4,36)=8.25, \mathrm{p}<0.001$, partial $\eta^{2}=0.48$, univariate $\mathrm{F}^{\prime} \mathrm{s}(1,39)>7.80$, p's $<0.008$, partial $\eta^{2, s}>0.17$

The partial return of contamination, and other CFFD measures was transient. They faded away within five trials. At the completion of the last exposure trials (i.e., trial 36), participants in both conditions reported large and significant reductions on all measures. Those in the E+SB group reported significantly less contamination than did the ERP participants. 


\section{Discussion}

The main prediction was that the E+SB procedure would produce significant reductions in feelings of contamination. This prediction was confirmed, and is supportive of the main hypothesis. In addition the secondary predictions were also supported. E+SB was followed by significant reductions in disgust, fear and danger.

The expectation that the ERP control condition would produce comparable, significant reductions was also supported. Only two differences between the results of the E+SB condition and the control ERP were obtained. The reduction of feelings of contamination in the E+SB condition exceeded the (also significant) reductions of feelings of contamination observed in the ERP group, and a transient return of contamination and fear was observed in the E+SB group.

The partial return of fear between sessions is a "robust and common phenomenon" (Rachman, 1989, p.147), especially in the early stages of treatment. This form of return of fear is rarely a problem and usually fades out after a small number of trials; ERP treatment is never withheld because of an expectation that transient returns of fear might occur between sessions. The other type of a return of fear, a major return of fear that occurs after a full, successful course of ERP, a clinical relapse, can be a serious problem but fortunately the use of booster sessions can be effective at minimizing or eliminating this phenomenon.

The prediction that the danger cognitions would be significantly reduced in both conditions is of interest because of the plausible concern that engaging in safety behaviour might preclude the disconfirmation of unadaptive cognitions. Significant and stable decreases in the danger reports were recorded in both conditions, thereby providing another exception to the expectation that safety behaviour necessarily impedes disconfirmations of maladaptive 
cognitions (Parrish, Radomsky \& Dugas, 2008; Rachman, Radomsky \& Shafran, 2008). Given that the ratings of danger were not large to begin with, this finding definitely requires replication; it is likely that after E+SB trials, the decrease in reports of danger will be magnified in groups that start with higher levels of danger (e.g. OCD patients).

The initial ratings of fear were relatively low but nevertheless showed a significant decline from pre-treatment to post-treatment. In a sample that shows larger fear initially, we expect that the fear-reducing effects of both E+SB and ERP will be magnified.

The relations between fear and disgust are complex and fascinating (Olatunji \& McKay, 2009), and the results of this experiment on contamination incidentally adds some new information on this subject. Disgust reactions to the contaminants were high to begin with, even in this non-clinical sample, but declined appreciably after treatment, especially in the $\mathrm{E}+\mathrm{SB}$ condition. They steeply reduced from 53.48 at trial one to a miniscule 6.93 at the terminating trial, number 36. Given the mixed results of psychological therapy for overcoming maladaptive disgust reactions (McKay \& Olatunji, 2010) it might be worthwhile following up this finding.

\section{$\underline{6.1 \text { Safety behaviour. }}$}

In many circumstances safety behaviour is anti-therapeutic, but we now have examples in which safety behaviour can facilitate treatment (Rachman, Radomsky \& Shafran, 2008). The present experiment is part of a programme of research designed to develop judicious forms of safety behaviour in order to facilitate the treatment of anxiety disorders, and ultimately extend to other disorders, such as depression, eating disorders. The programme of research is constructive and cautious.

The participants were not explicitly asked if the use of the wipes made them feel safer, partly because we were concerned that this might introduce a bias into the results, and because 
our priority was to find out if repeated trials of the wipe technique can indeed reduce the feelings of contamination. We make a weak inference from the positive results of the experiment that their use of the wipes method did make the participants feel safer, but a more satisfactory inference can be drawn from their decreases in danger and in fear.That argument must await replications in which the participants have high levels of danger and fear to begin with.

The fact that the OCD patients (see below), and the participants in this experiment, reported decreases in contamination and in fear, is encouraging but not sufficient. In due course it will be necessary to develop a specific measure of safety. It should be said that the results of the experiment and the case series rule out the possibility that after the E+SB exercises the patients and participants felt less safe.

\subsection{Common Factors?}

Significant reductions in contamination, disgust, fear and danger, took place in both conditions and the obvious common factor was repeated exposures. This raises the possibility that a common process might have been operating during ERP and in E+SB. That complex question requires specific investigation and will not be analysed here, but it is noteworthy that whatever process is underway, it does not require response prevention. Equally important, the results indicate that the use of safety behaviour does not impede the significant and stable reductions of contamination, disgust, fear or danger. A possible explanation that we hope to address in due course rests on the concept of controllability because there is abundant evidence of a close connection between fear and a sense of uncontrollability, and indicative evidence that gains in self-efficacy can reduce fear (Bandura, 1978). Safety behaviour, including the use of hygienic wipes in this experiment, may well promote an increasing and a realistic sense of control. 


\subsection{Experimental Implications of the Clinical Reports.}

It is customary when discussing the significance of experiments of this type, carried out with non-clinical participants, to consider the possible clinical implications, but in the present instance it was the clinical exploratory findings that gave rise to the experiment. This is a reversal of the more common process of moving from an experiment on to a consideration of possible clinical implications. It was the therapeutic success of using the hygienic-wipe safety behaviour in the exploratory treatment of 10 patients with a fear of contamination, accompanied by compulsive washing, which prompted the experiment. As mentioned earlier, a full description of this case series is in preparation. Eight of the 10 patients benefited from the treatment. All but two of the ten were severe and/or chronic cases of OCD. In four of the cases $\mathrm{E}+\mathrm{SB}$ was the primary component of treatment and in five cases the $\mathrm{E}+\mathrm{SB}$ was a component in a full course of cognitive behaviour therapy. At the end of treatment, which ranged from 6 sessions to 20 sessions, the fear of contamination and compulsive cleaning were significantly reduced in all but one of the patients, and their quality of life was enhanced. In no case was there a deterioration, or the emergence of new symptoms. None of the patients developed a dependency on the wipes. A partial return of fear occurred between sessions early in the course of treatment but in all cases it faded out and was never a problem. Follow-ups were conducted at 3 months for all of the patients and four of them were available for re-assessment one year after treatment. The improvements were well maintained.

The fact that eight of the ten patients benefited from the treatment, notwithstanding the absence of any response prevention, raised new interest in the role and function of ERP treatment for this form of obsessive compulsive disorder and led to the experimental analysis. There is 
overwhelming evidence that many patients with OCD benefit from ERP. For these many patients ERP is sufficient, and the new question is whether ERP is always necessary.

\subsection{Is response prevention always necessary?}

Our clinical observations, now supported by the results of this experiment, appear to indicate that ERP is indeed sufficient but not always necessary. In the present experiment the use of a safety behaviour produced remarkable results that border on the paradoxical, and may surprise not a few clinical researchers and clinicians. It must be emphasised that this work is at an early stage and we definitely do not recommend the clinical use of this safety behaviour until it has undergone rigorous testing. The appeal of this safety method, if confirmed, is that it may lead to the development of a gentler, more tolerable type of treatment, and reduce the unacceptably high dropout and refusal rates.

In their recent paper Chasson et alia (2010, p.675) correctly noted that "Exposure and response prevention (ERP) is considered the gold standard psychological intervention for OCD". It consists of two components, "systematic and prolonged exposure to anxietyprovoking stimuli and the simultaneous prevention of fear-reducing physical and mental actions" (Chasson et alia, 2010, p.675).

It will not pass un-noticed that in the present experiment the feelings of contamination, and associated disgust/fear/danger, were substantially reduced even when the response prevention (RP) component was omitted. This finding is consistent with our clinical observation that safety behaviour, without RP, can facilitate the treatment of OCD patients. These observations raise the possibility that the RP component may not be essential; sufficient in many instances but not always necessary. 
There is also a golden rule about the need to prevent escape behaviour. The idea is that patients must remain in the feared situation until their fear reduces; attempts to avoid or escape must be prevented. "The golden rule is to try never to leave a situation until the fear is going down" (original emphasis, Mathews, Gelder \& Johnston, 1981,p.182).

In early studies of therapeutic safety behaviour, de Silva and Rachman (1984) explained to a group of agoraphobic patients that they were free to escape from their exposure exercises (mainly in supermarkets) if their anxiety rose to intolerable levels. This exposure and safety behaviour proved to be as effective as a standard ERP treatment in reducing their fear, and did not strengthen the agoraphobic avoidance behaviour. Similar results were obtained in a replication study by Rachman, Craske, Tallman and Solyom (1986). The golden rule about preventing escape during exposure was not confirmed.

The recovery rates for OCD patients who receive ERP have remained static for many years and improvements in treatment efficacy are definitely needed (Wilhelm, 2000). As noted by Abramovitz (1997) and Coughtrey (2010), both CBT and ERP treatments yield low recovery rates, ranging between 25-62 \% (see also Eddy et al., 2004; and Fisher and Wells,2005) .

The formulation of the main hypothesis, that contamination can be reduced by Exposure plus safety behaviour (E+SB), was based on three reasons: Firstly, our exploratory work on developing judicious safety behaviours for the treatment of OCD patients with a fear of contamination led to the discovery that most of them improved even though the exposure exercises were not followed by response prevention. Secondly, a re-consideration of the fearreduction methods that were in use by pioneers such as Wolpe $(1958)$ and Bandura $(1969,1978)$ was a reminder that fears can be reduced even without a resort to response prevention. Thirdly, our positive findings on the fear-reducing effects of safety behaviour (de Silva and Rachman, 
1984; Milosevic \& Radomsky, 2008; Parrish, Radomsky \& Dugas, 2008; Rachman, Craske, Tallman and Solyom, 1986: Rachman, Radomsky \& Shafran, 2008) were obtained without a resort to response prevention. Evidently, fear can be reduced by repeated exposures without imposing response prevention. It is conceivable that as more emphatically cognitive treatments are developed, some of the problems encountered in using ERP will be circumvented.

The strengths of this experiment are its origin in the exploratory treatment of patients with OCD, and the boost which it gives to fresh thinking and research on safety behaviour. The weakness of the experiment is that it did not address the process/es involved in ERP and in ESB, and no measures pertaining to process (e.g., changes in controllability, feelings of safety) were included. In clinical and experimental research on this type of safety behaviour, we recommend the supplementary use of video clips for demonstrations and modelling. Our own videos were not employed in the experiment itself, but proved to be useful educational tools even though they were incontestably amateur. 
Author notes: We wish to thank M. van den Hout, H.C. Philips, A. Coughtrey, A. Hibbert, L. Young, A. Nichols and S. Lavoie for their advice/assistance. This work was supported in part by the Canadian Institutes of Health Research. 


\section{REFERENCES.}

Abramowitz, J.S. (1997). Effectiveness of psychological and pharmacological treatments for obsessive-compulsive disorder: A quantitative review. Journal of Consulting and Clinical Psychology, 65, 44-52.

Bandura, A. (1969). Principles of behaviour modification. New York: Holt, Rinehart \& Winston.

Bandura, A. (1978). Reflections on self-efficacy. In: S. Rachman, Editor, Perceived selfefficacy: Analyses of Bandura's theory of behavioural change. Advances in Behaviour Research and Therapy, 1, 237-269.

Barlow,D. (2001). Anxiety and its Disorders, Second edition: The nature and treatment of anxiety and panic. New York, NY: Guilford Press.Beck, J., \& Steer, RA (1990). Beck Anxiety Inventory manual. San Antonio, TX: Psychological Corporation.

Chasson, G.S., Buhlmann, U., Tolin, D.F., Rao, S.R., Reese, H.E., Rowley, T., Welsh, K.S., \& Wilhelm, S. (2010). Need for speed: Evaluating slopes of OCD recovery in behaviour therapy enhanced with D-cycloserine. Behaviour Research and Therapy, 48, 675-679.

Clark, D.A. (2004). Cognitive-behavioral therapy for OCD. New York, NY: Guilford Press.

Chorpita, B.F., \& Barlow, D.H. (1998). The development of anxiety: The role of control in the early environment. Psychoogical Bulletin, 124, 3-21.

Cottraux, J., Bouvard, M.A., \& Milhery, M. (2005). Combining pharmacotherapy with cognitive-behavioural interventions for obsessive-compulsive disorder. Cognitive Behaviour Therapy, 34, 185-192.

Coughtrey, A.E. (2010). Mental contamination in obsessive-compulsive disorder. Doctoral dissertation completed under the supervision of R. Shafran, University of Reading, U.K.

Craske, M. (1999). Anxiety Disorders._Boulder,CO: Westview Press.

De Silva, P., \& Rachman, S. (1984). Does escape behavior strengthen agoraphobic avoidance? A preliminary study, Behaviour Research and Therapy, 22, 87-91.

Eddy, K., Dutra, L., Bradley, R., \& Western, D. (2004). A multi-dimensional meta-analysis of psychotherapy and pharmacotherapy for OCD. Clinical Psychology Review, 24, 10111030.

Fairburn, C. G. (1997). Interpersonal psychotherapy for bulimia nervosa. In D.M. Garner, \& P.E. Garfinkel (Eds.), Handbook of Treatment for Eating Disorders, $2^{\text {nd }}$ Edition (pp. 278294). New York, NY: Guilford. 
Fisher, P., \& Wells, A. (2005). How effective are cognitive and behavioural treatments for OCD? A clinical significance analysis. Behaviour Research and Therapy, 43, 15431558.

Foa, E.B., Liebowitz, M.R., Kozak, M.J., Davies, S., Campeas, R., Franklin, M.E., Huppert, J.D., Kjernisted, K., Rowan, V., Schmidt, A.B., Simpson, H.B., \& Tu, X. (2005). Randomized, placebo-controlled trial of exposure and ritual prevention, clomipramine, and their combination in the treatment of obsessive-compulsive disorder. American Journal of Psychiatry, 162, 151-161.

International Obsessive-compulsive Foundation. (2009). What you need to know about Obsessive Compulsive Disorder. Retrieved from http://ocfoundation.org/uploadedFiles/WhatYouNeed_09.pdf

Jenike, M.A., Baer, L., \& Minichiello, W.E. (1998). Obsessive-compulsive disorders: Practical management. St. Louis: Mosby.

Mathews, A.M., Gelder, M.G., \& Johnston, D.W. (1981). Agorophobia: Nature and Treatment. New York, NY: Guildford Press.

McKay,D., \& Olatunji, B. (Editors). (2010). Disgust and Psychopathology: Introduction to Part II of the special series. International Journal of Cognitive Therapy, 3, 1-63.

Meyer, V. (1966). Modification of expectations in cases with obsessional rituals. Behaviour Research and Therapy, 39, 457-464.

Milosevic, I. \& Radomsky, A.S. (2008). Safety behaviour does not necessarily interfere with exposure therapy. Behaviour Research and Therapy, 46, 1111-1118.

Moulding, R., \& Kyrios. M. (2006). Anxiety disorders and control-related beliefs: The exemplar of obsessive-compulsive disorder (OCD). Clinical Psychology Review, 26, 573-583.

National Institute for Health and Clinical Excellence. (2005). Core interventions in the treatment of obsessive-compulsive disorder and body dysmorphic disorder. National Clinical Practice Guideline Number 31. Retrieved from http://www.nice.org.uk/nicemedia/live/10976/29947/29947.pdf

National Institute of Mental Health. (2009). Anxiety Disorders booklet. Retrieved from http://www.nimh.nih.gov/health/publications/anxiety-disorders/nimhanxiety.pdf

Obsessive Compulsive Cognitions Working Group (1997). Cognitive assessment of obsessivecompulsive disorder. Behaviour Research and Therapy, 35, 667-681.

Olatunji, B. O., \& McKay, D. (2009). Disgust and its disorders: Theory, assessment, and treatment implications. Washington, DC: American Psychological Association. 
Parrish, C.L., Radomsky, A.S., \& Dugas, M.J. (2008). Anxiety-control strategies: Is there room for neutralizing behavior in successful exposure treatment? Clinical Psychology Review, $28,1400-1412$.

Rachman,S. (1989). The Return of Fear: Review and prospect. Clinical Psychology Review, 9 , 147-168.

Rachman, S. (2003). The treatment of obsessions. Oxford: Oxford University Press.

Rachman, S., Cobb, J., Grey, S., McDonald, B., Mawson, D., Sartory, G., \& Stern, R. (1979). The behavioural treatment of obsessional-compulsive disorders, with and without clomipramine. Behaviour Research and Therapy, 17, 467-478.

Rachman, S., Craske, M., Tallman, K., \& Solyom, C. (1986). Does escape behavior strengthen agoraphobic avoidance? Behavior Therapy, 17, 366-384.

Rachman, S., \& Hodgson, R.J. (1980). Obsessions and compulsions. Englewood Cliffs, NJ: Prentice-Hall.

Rachman, S., Radomsky, A.S., \& Shafran, S. (2008). Safety behaviour: A reconsideration. Behaviour Research \& Therapy, 46, 163-173.

Radomsky, A.S., Shafran, R., Coughtrey, A.E., \& Rachman, S. (2010). Cognitive-behavior therapy for compulsive checking in OCD. Cognitive and Behavioral Practice, 17, 119131.

Salkovskis, P. (1991). The importance of behaviour in the maintenance of anxiety and panic: A cognitive account. Behavioural Psychotherapy, 19, 6-19.

Stanley, M.A., \& Turner, S.M. (1995). Current status of pharmacological and behavioural treatment of obsessive-compulsive disorder. Behaviour Therapy, 26, 163-186.

Taylor, S. , Abramowitz, J.S., McKay, D., Calamari, J.E., Sookman, D., Kyrios, M., Wilhelm, S., \& Carmin, C. (2006). Do dysfunctional beliefs play a role in all types of obsessive compulsive disorder? Journal of Anxiety Disorders, 20, 85-97.

Tolin, D. F., Woods, C. M., \& Abramowitz, J. S. (2003). Relationship between obsessive beliefs and obsessive-compulsive symptoms. Cognitive Therapy and Research, 27, 657-669.

Whittal, M.L., Thordarson, D.S., \& McLean, P.D. (2005). Treatment of obsessive-compulsive disorder: Cognitive behaviour therapy vs. exposure and response prevention. Behaviour Research and Therapy, 43, 1559-1576. 
Whittal, M.L., Woody, S.R., McLean, P.D., Rachman, S., \& Robichaud, M. (2010). Treatment of obsessions: A randomised controlled trial. Behaviour Research and Therapy, 48, 295303.

Wilhelm, S. (2000). Cognitive therapy for obsessive-compulsive disorder. Journal of Cognitive Psychotherapy, 14, 245-259.

Wolpe, J. (1958). Psychotherapy by reciprocal inhibition. Stanford: Stanford University Press. 
Table 1. Mean Ratings (and Standard Deviations) of Contamination, Fear, Danger and Disgust (on a 0 to 100 scale) at the Beginning and End of the Two Sessions

\begin{tabular}{|c|c|c|c|c|c|c|c|c|}
\hline & \multicolumn{2}{|c|}{ Visit 1} & \multicolumn{2}{|c|}{ Visit 1} & \multicolumn{2}{|c|}{ Visit 2} & \multicolumn{2}{|c|}{ Visit 2} \\
\hline & \multicolumn{2}{|c|}{ Trial 1} & \multicolumn{2}{|c|}{ Trial 20} & \multicolumn{2}{|c|}{ Trial 1} & \multicolumn{2}{|c|}{ Trial 16} \\
\hline Condition & $E+R P$ & $\mathrm{E}+\mathrm{SB}$ & $\mathrm{E}+\mathrm{RP}$ & $\mathrm{E}+\mathrm{SB}$ & $E+R P$ & $\mathrm{E}+\mathrm{SB}$ & $\mathrm{E}+\mathrm{RP}$ & $\mathrm{E}+\mathrm{SB}$ \\
\hline \multirow[t]{2}{*}{ Contamination } & 67.58 & 61.13 & 51.95 & 9.50 & 47.55 & 37.90 & 41.93 & 8.65 \\
\hline & (29.63) & (25.51) & (33.29) & (16.74) & (27.95) & $(29.58)$ & (31.12) & (17.65) \\
\hline \multirow[t]{2}{*}{ Fear } & 31.18 & 26.10 & 7.53 & 2.88 & 11.25 & 14.50 & 3.88 & 2.95 \\
\hline & $(32.08)$ & $(26.17)$ & (16.93) & $(7.73)$ & (18.56) & $(20.09)$ & (10.76) & (10.29) \\
\hline \multirow[t]{2}{*}{ Danger } & 25.75 & 20.80 & 10.53 & 0.88 & 13.00 & 11.40 & 6.30 & 2.40 \\
\hline & $(32.67)$ & $(24.76)$ & $(24.19)$ & $(3.32)$ & $(23.34)$ & $(17.01)$ & (18.63) & $(8.84)$ \\
\hline \multirow[t]{2}{*}{ Disgust } & 87.80 & 53.48 & 42.93 & 6.48 & 37.13 & 32.48 & 30.95 & 6.93 \\
\hline & $(150.75)$ & (31.93) & $(31.48)$ & (13.57) & (28.64) & $(31.96)$ & (26.89) & $(15.85)$ \\
\hline
\end{tabular}


Figure 1 - Mean Ratings of Contamination (on a 0 to 100 scale) at the Beginning and End of the Two Sessions

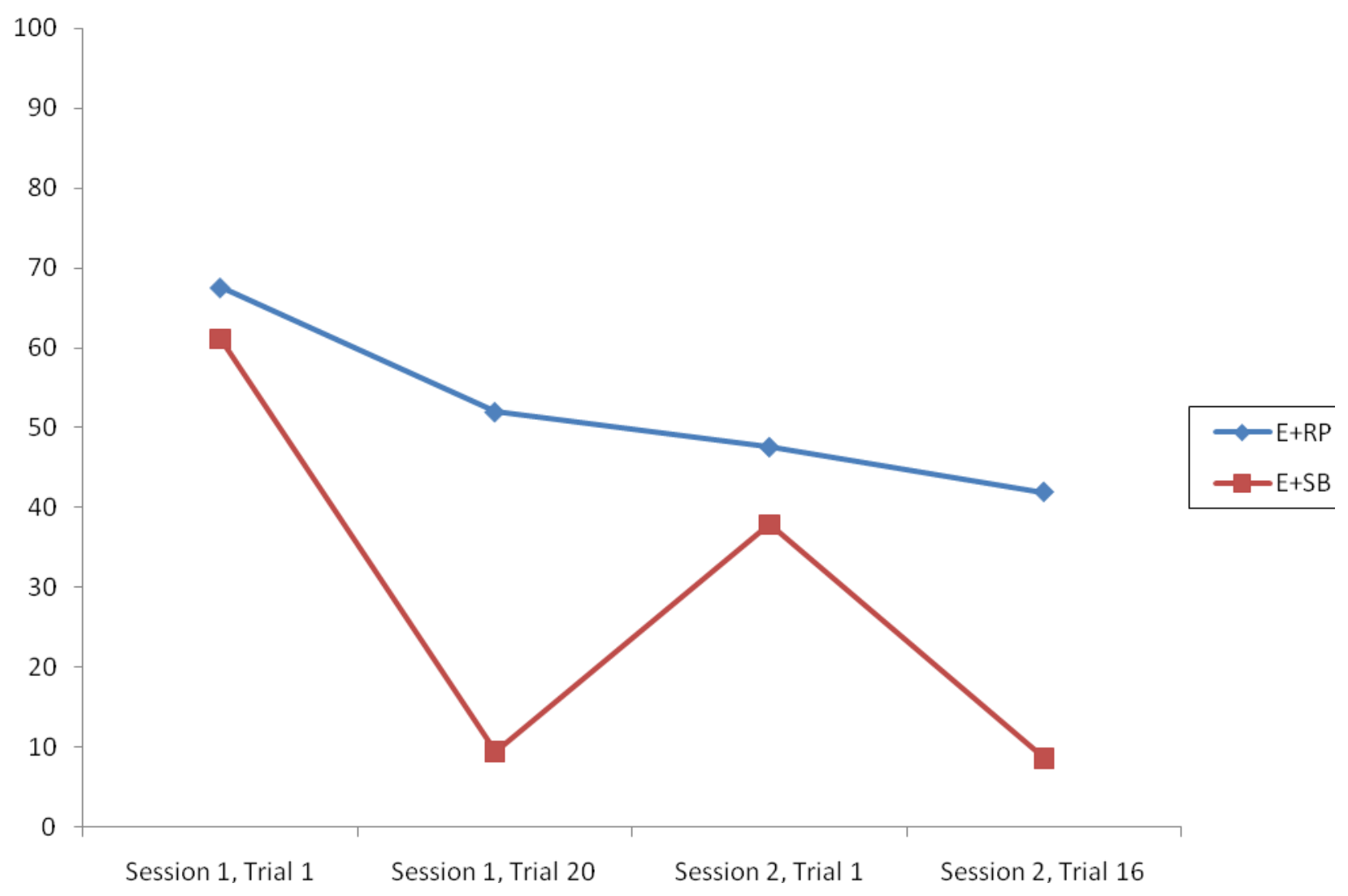


Figure 2 - Mean Ratings of Fear (on a 0 to 100 scale) at the Beginning and End of the Two

\section{Sessions}

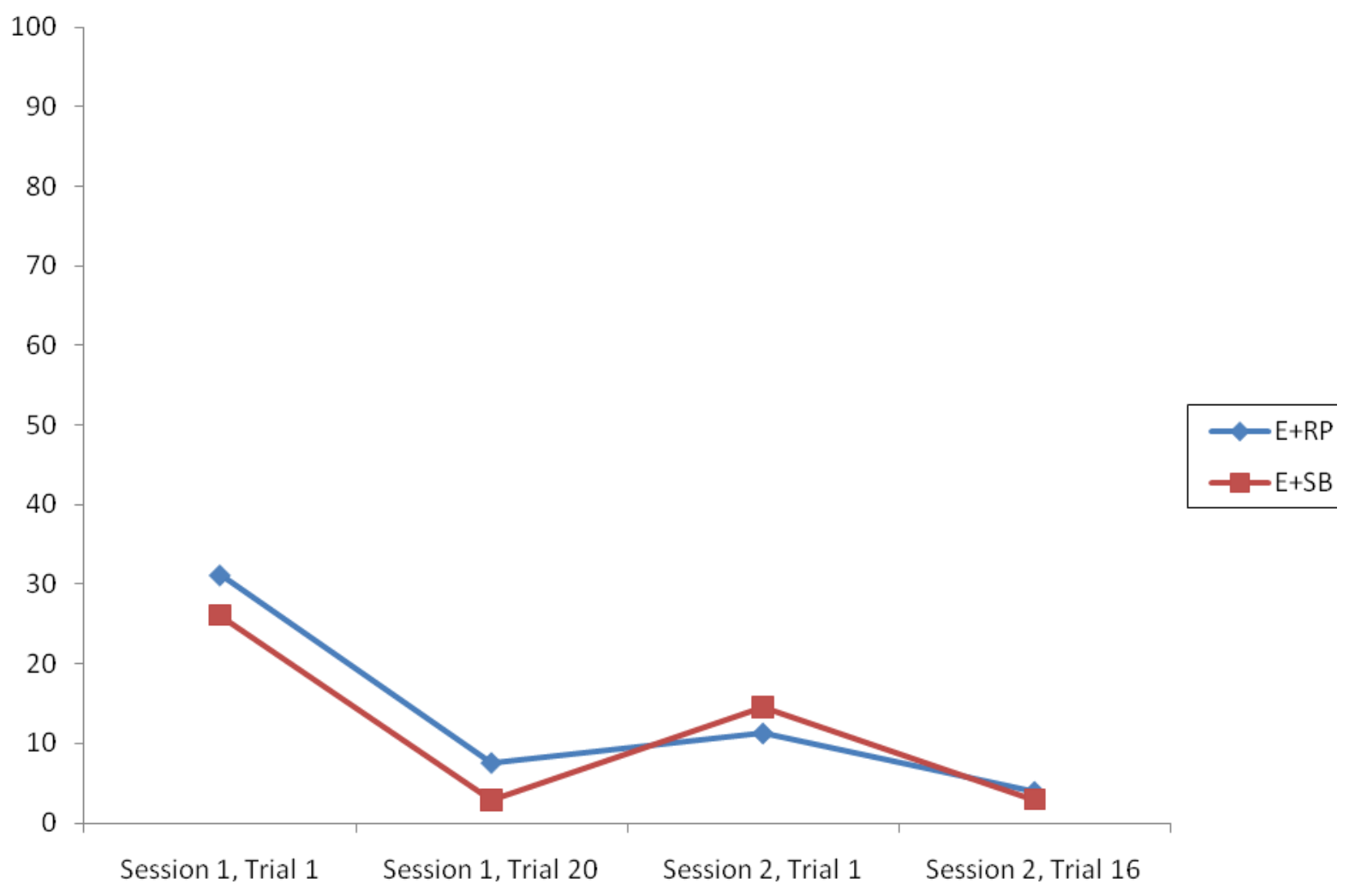


Figure 3 - Mean Ratings of Danger (on a 0 to 100 scale) at the Beginning and End of the Two

\section{Sessions}

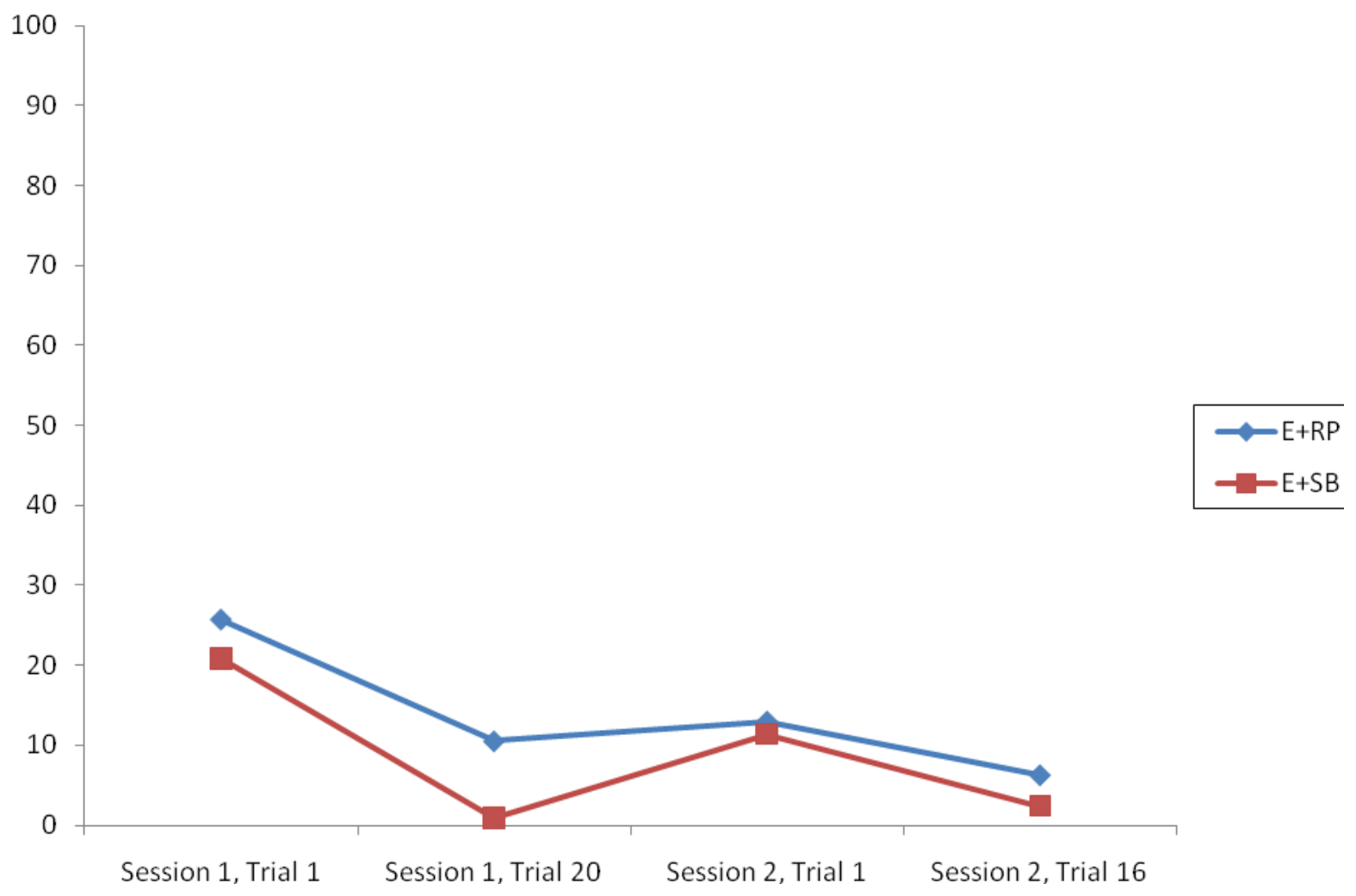


Figure 4 - Mean Ratings of Disgust (on a 0 to 100 scale) at the Beginning and End of the Two

\section{Sessions}

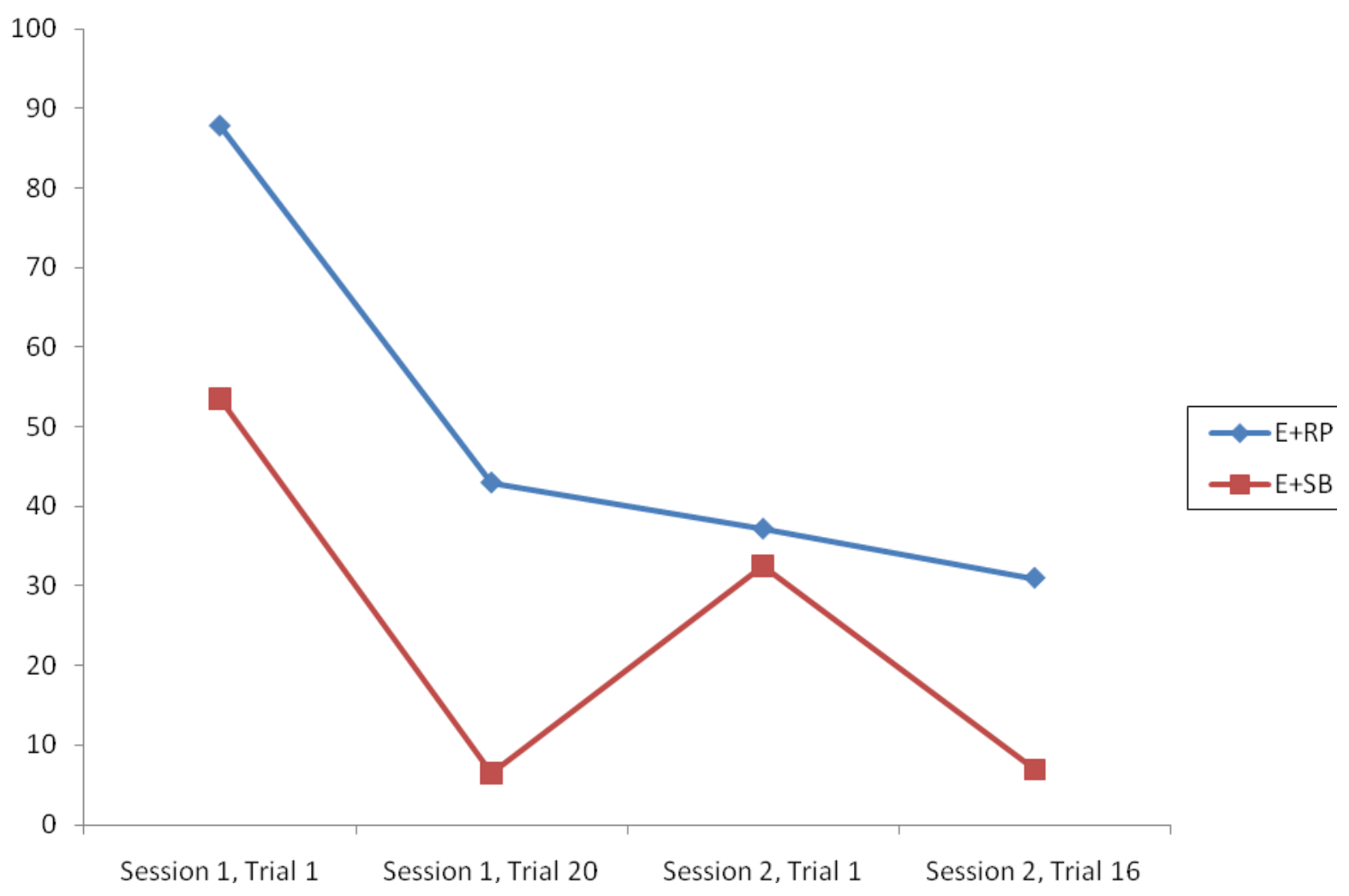

